Check for updates

Cite this: RSC Adv., 2017, 7, 47063

Received 5th June 2017

Accepted 29th September 2017

DOI: $10.1039 / \mathrm{c} 7 \mathrm{ra06290g}$

rsc.li/rsc-advances

\section{A dynamic prediction of stability for nitromethane in external electric field $\dagger$}

\author{
Fu-de Ren, (DD *a Duan-lin Cao, ${ }^{a}$ Wen-jing Shi ${ }^{\mathrm{b}}$ and Min You ${ }^{\mathrm{a}}$
}

Adding an external electric field into an energetic material system can increase the energy but the stability may be reduced. In this paper, the effects of external electric fields on the initiation reaction dynamics of $\mathrm{CH}_{3} \mathrm{NO}_{2}$ (intermolecular and 1,3-intramolecular hydrogen transferences) were investigated using the MP2/6-311++G(2d,p) and CCSD/6-311++G(2d,p) methods. The results show that, when the external electric field is in the $-y$-direction of the $\mathrm{CH}_{3} \mathrm{NO}_{2}$ dimer (perpendicular to the $\mathrm{O} \cdots \mathrm{N} \cdots \mathrm{N}$ plane), the barriers of intermolecular hydrogen transference are lower than the $\mathrm{C}-\mathrm{NO}_{2}$ bond dissociation energies, leading to a preference for the hydrogen transference path over the $\mathrm{C}-\mathrm{NO}_{2}$ bond dissociation, and the sensitivities are higher than in the absence of an external electric field. However, in the other fields (except for the $\mathrm{C}-\mathrm{NO}_{2}$ bond axis direction with a field strength larger than +0.0060 a.u.), the $\mathrm{C}-\mathrm{NO}_{2}$ bond scission is favored and the sensitivities are almost equal to those in the absence of an external electric field. Although due to many obstacles, at present the proposition of adjusting the explosive sensitivity with external electric field does not make any sense in practice, the external-electric-field effect on explosive sensitivity must arouse intense interest in future.

\section{Introduction}

Although adding an external electric field into an energetic material system can increase the energy content of conduction gases in the vicinity of the detonation front and consequently accelerate detonation velocity and enhance detonation pressure, ${ }^{1-3}$ the stability of an energetic material may be reduced, leading to an increased explosive sensitivity.

There are mainly two reasons for reducing the stability of explosives. One is that the external electric field may elongate the bond length and reduce the bond dissociation energy (BDE) of the "trigger linkage", 4,5 the breaking of which is a key factor in the initiation of detonation..$^{6-9}$ Thus, the trigger linkage is more prone to breakage in an external electric field than in the absence of an external electric field, leading to a higher explosive sensitivity. The other is that the external electric field may lower the activation energy of chemical reactions. ${ }^{10}$ For an explosive molecule, if the external electric field lowers the activation energy of the first step of the reaction (i.e., the detonation initiation), decomposition will be easier, and thus explosive sensitivity will become higher. The lower the

${ }^{a}$ College of Chemical Engineering and Environment, North University of China, Taiyuan 030051, China. E-mail: fdren888@126.com; Fax: +86 351 3922117; Tel: +863513922117

${ }^{b}$ The Third Hospital of Shanxi Medical University, Taiyuan 030053, China $\dagger$ Electronic supplementary information (ESI) available: The optimized geometrical parameters and AIM results of reactants, TS-2, TS-3, and the C- $\mathrm{NO}_{2}$ BDEs and barriers of three paths in different field strengths and orientations at the different levels of theory. See DOI: $10.1039 / \mathrm{c} 7 \mathrm{ra} 06290 \mathrm{~g}$ activation energy, the more susceptibly the detonation initiation occurs, accompanied by a higher explosive sensitivity. ${ }^{7-9}$ Indeed, in our recent dynamic prediction of nitromethane $\rightarrow$ methyl nitrite isomerization in an external electric field, the barrier heights were decreased and the explosive sensitivities were increased with the increase of the electric field in the $-x$ direction..$^{11}$ Therefore, in order to predict the stability of an explosive molecule in an external electric field, it is necessary to examine the changes in the strength of the trigger linkage and the activation energy of detonation initiation.

Nitromethane $\left(\mathrm{CH}_{3}-\mathrm{NO}_{2}\right)$ is a prototypical explosive. Its decomposition mechanism has been extensively investigated in the absence of external electric field. ${ }^{12-20}$ Due to the lowest $\mathrm{C}-\mathrm{NO}_{2}$ BDE, the $\mathrm{C}-\mathrm{NO}_{2}$ bond scission was regarded as the first step. ${ }^{12}$ However, the viewpoint that the 1,3-intramolecular hydrogen transference and oxygen transfer from the nitro to methyl group were prior to the $\mathrm{C}-\mathrm{NO}_{2}$ bond scission was supported based on the first principle. ${ }^{13-16,18}$ Then, what about in the presence of external electric field? Furthermore, will the sensitivity be increased in the external electric field? Recently, we investigated the changes of the $\mathrm{C}-\mathrm{NO}_{2}$ BDEs and the barriers of $\mathrm{CH}_{3} \mathrm{NO}_{2} \rightarrow$ $\mathrm{CH}_{3} \mathrm{ONO}$ isomerization in the presence of external electric field using the MP2 and CCSD methods. ${ }^{11}$ To our knowledge, few theoretical investigations on the stability and sensitivity of explosive molecule in external electric field were presented.

The hydrogen transference is a typical reaction mechanism. In this work, a dynamic investigation into the effect of external electric field on the intramolecular and intermolecular hydrogen transferences in detonation initiation of 
nitromethane was presented. The changes of the stability and explosive sensitivity were predicted according to the change of activation energy in external electric field. This investigation must be useful to add efficiently electric field to the energetic material system to avoid the catastrophic explosion in external electric field.

\section{Computational details}

All calculations were performed with Gaussian 03 programs. ${ }^{21}$ All the reactants and transition states (TS) were fully optimized using the MP2/6-311++G(2d,p) method in external electric fields (as well as no field). Energy minima of them were confirmed by the absence of imaginary frequency and only one imaginary frequency, respectively. The rate constants for each reaction path were calculated in the different field strengths and orientations at the MP2/6-311++G(2d,p) level, and AIM (atoms in molecules $)^{22,23}$ results were obtained at the same level of theory. The activation energies were evaluated at the CCSD/6311++G(2d,p)//MP2/6-311++G(2d,p) level.

In the coordinate systems used for the dynamic analysis of the reaction paths of 1,3-intramolecular hydrogen transference, the carbon is at the origin and the nitrogen is on the $+z$-axis; the $x$-axis is in the $\mathrm{C}-\mathrm{NO}_{2}$ plane and the $y$-axis is perpendicular to it. For the intermolecular hydrogen transference, the $\mathrm{N} 2 \cdots \mathrm{N} 2^{\prime}$ orientation is on the $z$-axis, with $z$ increasing from $\mathrm{N} 2$ to $\mathrm{N} 2^{\prime}$ for all the $\mathrm{CH}_{3} \mathrm{NO}_{2}$ dimers. The $x$-axis is in the $\mathrm{O} 4 \cdots \mathrm{N} 2 \cdots \mathrm{N} 2^{\prime}$ plane, and the $y$-axis is perpendicular to it (see Fig. 1). In three orthogonal directions ( $x, y$, and $z$ ), the field strengths of \pm 0.002 , $\pm 0.004, \pm 0.006, \pm 0.008$ and \pm 0.010 a.u. were considered.

According to literature, ${ }^{\mathbf{1 0}}$ in the absence and presence of various field strengths, conventional transition state theory $(\mathrm{CTST})^{24,25}$ with wigner tunneling correction ${ }^{26-28}$ was used to provide estimates of the rate constants.

\section{Results and discussion}

In the absence of external electric field, three kinds of feasible mechanisms of the first step of the $\mathrm{CH}_{3} \mathrm{NO}_{2}$ decomposition are shown in Fig. 1: unimolecular isomerization to trans-eclipsed methyl nitrite $\mathrm{CH}_{3} \mathrm{ONO}$ via TS1, ${ }^{11}$ 1,3-intramolecular hydrogen transference to $\mathrm{C}_{1}$ symmetrical aci-nitromethane $\mathrm{CH}_{2} \mathrm{~N}(\mathrm{O}) \mathrm{OH}$ via TS2 and intermolecular hydrogen transfer via TS3. The barriers of TS2 and TS3 are 285.11 and $274.82 \mathrm{~kJ} \mathrm{~mol}^{-1}$ at the CCSD/6-311++G(2d,p)//MP2/6-311++G(2d,p) level, respectively. The $\mathrm{C}-\mathrm{NO}_{2} \mathrm{BDE}\left(275.21 \mathrm{~kJ} \mathrm{~mol}^{-1}\right)$ is lower than the barrier of $\mathrm{CH}_{3} \mathrm{NO}_{2} \rightarrow \mathrm{CH}_{3} \mathrm{ONO}^{11}$ or $\mathrm{CH}_{3} \mathrm{NO}_{2} \rightarrow \mathrm{CH}_{2} \mathrm{~N}(\mathrm{O}) \mathrm{OH}$, but slightly higher than that of the intermolecular hydrogen transfer.

Note that the hydrogen transference is the initiation reaction in the decomposition process of nitromethane. ${ }^{19}$ So the following sections only give a comparison of the effect of external electric field on the barrier heights of intramolecular and intermolecular hydrogen transference reaction paths with the $\mathrm{C}-\mathrm{NO}_{2}$ BDEs (see ESI data, Table $\mathrm{S} 1 \dagger$ ) in the different field strengths and orientations. For comparison, the results of "nitromethane $\rightarrow$ methyl nitrite $\mathrm{CH}_{3} \mathrm{ONO}$ via TS1 (ref. 11)" is also cited (see Fig. 1 and 2).

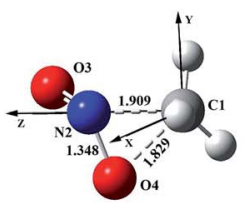

TS-1 (without field)

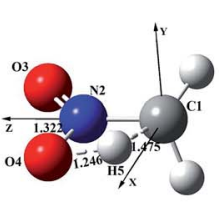

TS-2 (without field)

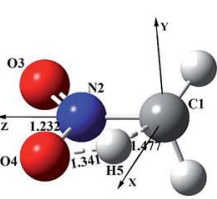

TS-2 ( $x+0.010$ a.u. $)$

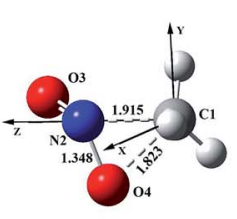

TS-1 ( $x-0.010$ a.u.)

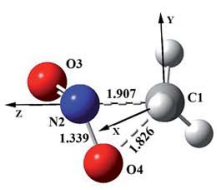

TS-1 ( $y+0.010$ a.u. $)$

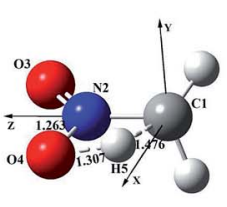

TS-2 ( $x-0.010$ a.u. $)$

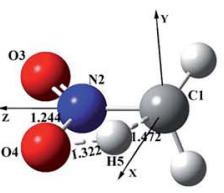

TS-2 $(y+0.010$ a.u. $)$

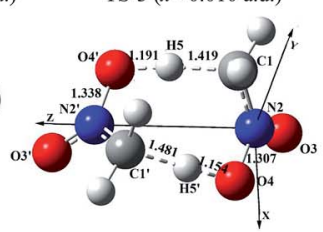

TS-3 ( $x-0.010$ a.u.)

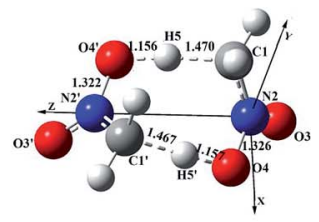

TS-3 (y+0.010 a.u.)

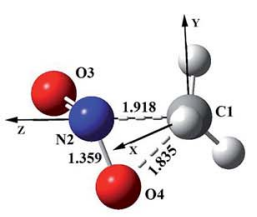

TS-1 (y -0.010 a.u.)

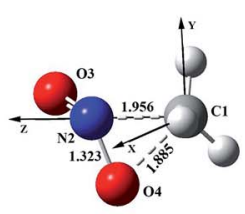

TS-1 ( $z+0.010$ a.u. $)$

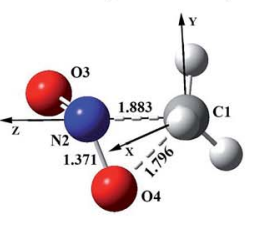

TS-1 ( $z-0.010$ a.u.)

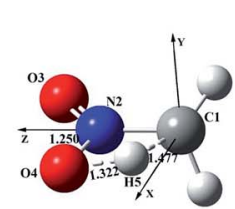

TS-2 ( $y-0.010$ a.u.)

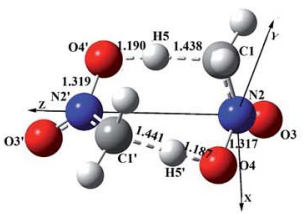

TS-3 (y - 0.010 a.u.)

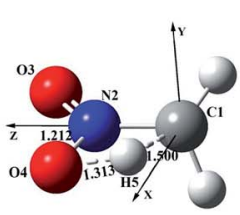

TS-2 ( $z+0.010$ a.u.)

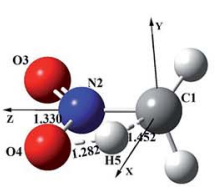

TS-2 ( $z-0.010$ a.u.)

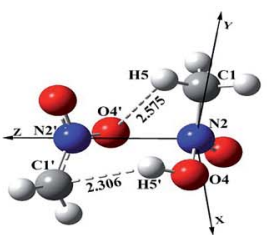

TS-3 (z+0.006 a.u.)

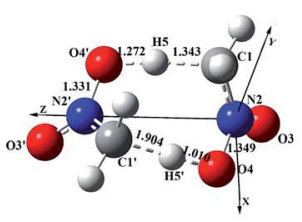

TS-3 (z-0.010 a.u.)
Fig. 1 Selected structures of the transition states in the different external electric field strengths and orientations (including those in the absence of field) at the MP2/6-311++G(2d,p) level (geometric parameters are in $\AA$ ) (the figures of TS-1 are from literature ${ }^{11}$ ).

\subsection{1,3-Intramolecular hydrogen transference}

The fields parallel to the $x$-axis affect the barrier heights more than those parallel to the $y$ - or $z$-axis. From Table S2 (see ESI data $\dagger$ ) and Fig. 2, in the presence of the field in the $y$ - or $z$-direction, 

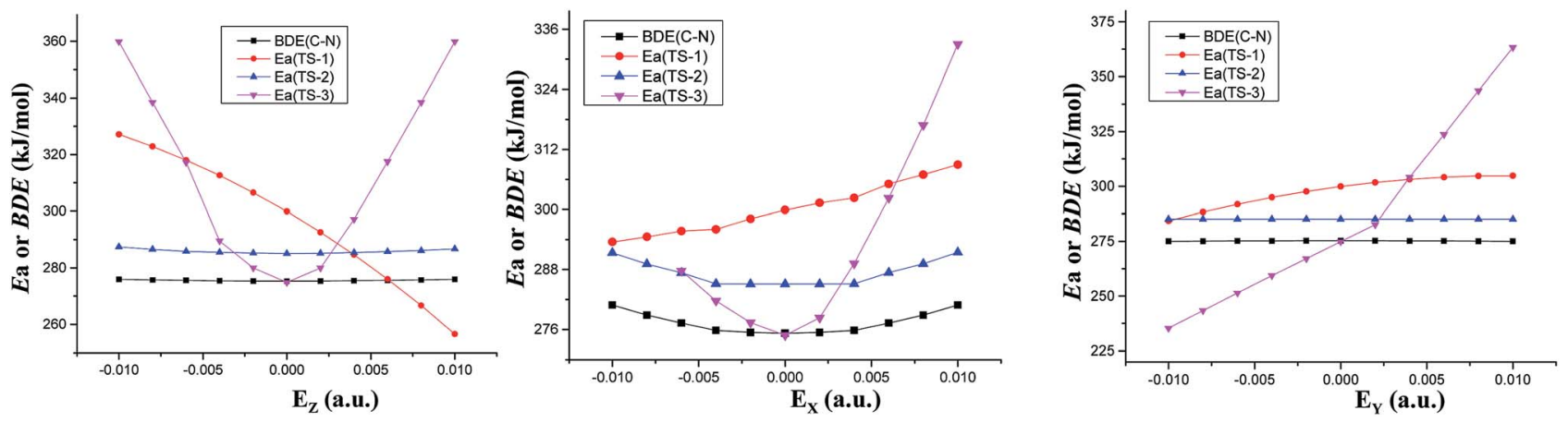

Fig. 2 Barriers $\left(E_{\mathrm{a}}\right)$ of three decomposition paths or $\mathrm{C}-\mathrm{NO}_{2}$ BDEs versus field strengths in the different field orientations $\left(E_{X}, E_{Y}\right.$ and $\left.E_{Z}\right)$ at the CCSD/6-311++G(2d,p)//MP2/6-311++G(2d,p) level.

barrier heights remain essentially unchanged even in the stronger electric fields. Furthermore, in the $x$-, $y$ - and $z$-oriented fields, the barriers are all higher than the $\mathrm{C}-\mathrm{NO}_{2}$ BDEs, showing that the external electric field causes preference of the $\mathrm{C}-\mathrm{NO}_{2}$ bond dissociation over the 1,3-intramolecular hydrogen transference.

For TS2, the $\mathrm{C} 1 \cdots \mathrm{H} 5$ distances do not show unambiguous trends with the changes of field strengths in the $x$-direction (see ESI data, Table S $3 \dagger$ ). As the field is increased in the $+x$-direction, the $\mathrm{N} 2-\mathrm{O} 4$ bond lengths increase, while the $\mathrm{O} 4 \cdots \mathrm{H} 5$ distances decrease, as is in accordance with the AIM results. The opposite trends are found in the $-x$-direction. In the $+z$-direction, as the field is increased, the $\mathrm{C} 1 \cdots \mathrm{H} 5$ distances decrease, while the $\mathrm{O} 4 \cdots \mathrm{H} 5$ distances and $\mathrm{N} 2-\mathrm{O} 4$ bond lengths increase. Fields in the negative $z$-direction correspondingly show the opposite trends. From Fig. 3 and 4 , in the $x$-direction, the linear correlations between the changes of bond lengths or corresponding electron densities and field strengths are found with the $R^{2}$ equal to the range of $0.9954-0.9966$ or $0.9968-0.9977$. In the $z$-direction, several good $\left(R^{2}=0.9991-0.9997\right.$ or $\left.0.9993-0.9999\right)$ linear correlations between them are also observed. However, in the $y$-direction, the linear correlation is not obvious.

From Table 1, fields oriented parallel to the $x$ - or $y$-axes have a minor effect on the imaginary vibrations, while fields along the $z$-direction, i.e. the direction of proton transfer, have a significant effect on them. The imaginary frequencies are decreased in the $-z$-direction while are increased in the $+z$ direction. Thus, the field-induced flattening of the potential energy surface is suggested in the $-z$-direction.

The Wigner corrections are in the range of about 5.2-6.2 at $298.15 \mathrm{~K}$, suggesting the notable tunneling-corrected effects on rate constants. However, at $688 \mathrm{~K}$, they are no more than 2.0 , indicating the weakened tunneling-corrected effects (see Table 1). A good $\left(R^{2}=0.9972\right)$ linear correlation is obtained between the tunneling-corrected rate constants and the $z$-field strengths (see Fig. 5). They fit the following equation:

$$
k_{298.15(\text { corrected) }}=-335.0 E_{z}+6.45
$$

\subsection{Intermolecular hydrogen transference}

In previous experimental and theoretical investigations, three bimolecular mechanisms with head-to-tail transition state geometry ( $\mathrm{C}-\mathrm{N}$ bond collinear) of two nitromethane molecules were discussed. ${ }^{29-31}$ The first reaction pathway resulted in the simultaneous production of nitrosomethane, formaldehyde and HONO with the unrealistically high activation energy $\left(497.7 \mathrm{~kJ} \mathrm{~mol}^{-1}\right) .{ }^{31}$ The second reaction pathway involved an association reaction joining two nitromethane molecules in a rearranged dimer formed by the intermolecular H-bonding interaction between the hydrogen and oxygen atoms, which led to a $\mathrm{CH}_{3}-\mathrm{N}(\mathrm{OH})-\mathrm{CH}(\mathrm{OH})-\mathrm{NO}_{2}$ product. However, this mechanism did not provide a direct pathway to the production of broadband absorbing species. ${ }^{32}$ The third models involved a bimolecular exchange of an oxygen atom to form nitrosomethane and nitromethanol. ${ }^{29}$ For this model, we have obtained a very high activation energy, in excess of $300.0 \mathrm{~kJ} \mathrm{~mol}^{-1}$ at the MP2/6-311++G(2d,p) level. Due to the very high activation energies of above three paths, Zeman et al. stated that the bimolecular reactions in the initiation of nitromethane were not probable. ${ }^{33}$ Therefore, above three bimolecular mechanisms were not considered in this work.

However, in this work, a new bimolecular side by side $\mathrm{C}_{1}$ symmetry $\mathrm{CH}_{3} \mathrm{NO}_{2}$ dimer transition state, TS3, formed by two intermolecular $\mathrm{H}$-bonds between the hydrogen and oxygen atoms is found (see Fig. 1). IRC calculation confirms the transformation from a side-by-side nitromethane dimer to a side-by-side aci-nitromethane dimer. In the absence of external electric field, the barrier is far lower than those in the previous bimolecular mechanisms, ${ }^{31-33}$ indicating that this mechanism may be the most favored bimolecular reaction pathway. Furthermore, as mentioned above, the barrier of TS3 is lower slightly than the $\mathrm{C}-\mathrm{NO}_{2} \mathrm{BDE}$, showing that this pathway might occur in the most competition with the $\mathrm{C}-\mathrm{NO}_{2}$ bond rupture at the initial stage of $\mathrm{CH}_{3} \mathrm{NO}_{2}$ decomposition.

The previous calculations of $\mathrm{CH}_{3} \mathrm{NO}_{2}$ dimer using the MINDO/3-HB technique indicated that a cyclic dimer, in which four weak intermolecular $\mathrm{H}$-bonds were formed, was energetically most favorable. ${ }^{34}$ However, at the MP2/6-311++G(2d,p) level, this structure is not obtained but a stable $\mathrm{CH}_{3} \mathrm{NO}_{2}$ dimer with only two intermolecular $\mathrm{H}$-bonds is found with $\mathrm{C}_{1}$ point group symmetry by unequal $\mathrm{H} \cdots \mathrm{O}$ distances (see ESI data, Fig. S1†). IRC calculation confirms the transformation from it to a side-by-side geometry aci-nitromethane dimer via TS3. For this reactant, the intermolecular $\mathrm{O}^{\prime} \cdots \mathrm{H} 5$ (or $\mathrm{O}^{\prime} \cdots \mathrm{H}^{\prime}$ ) 

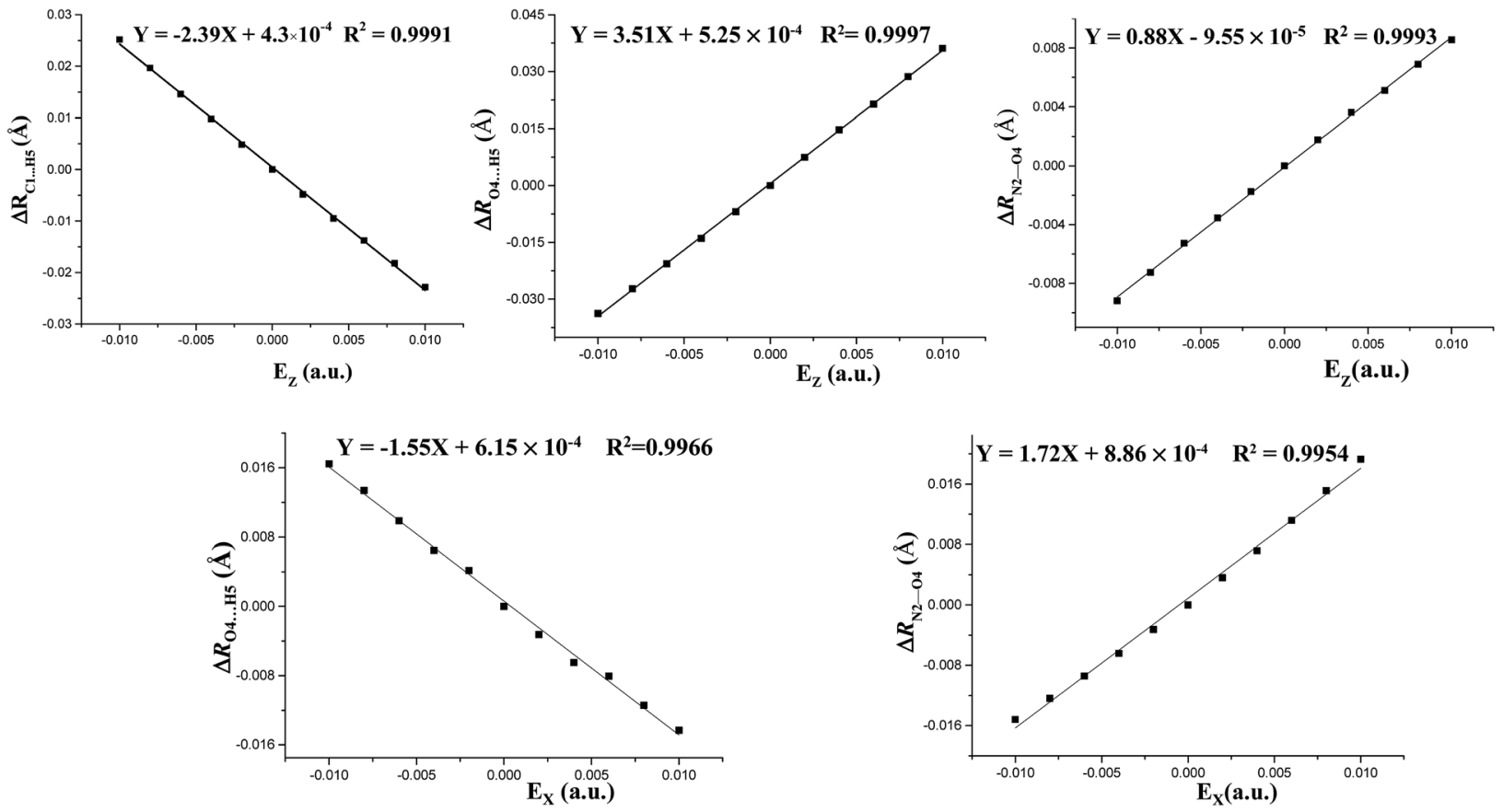

TS-2
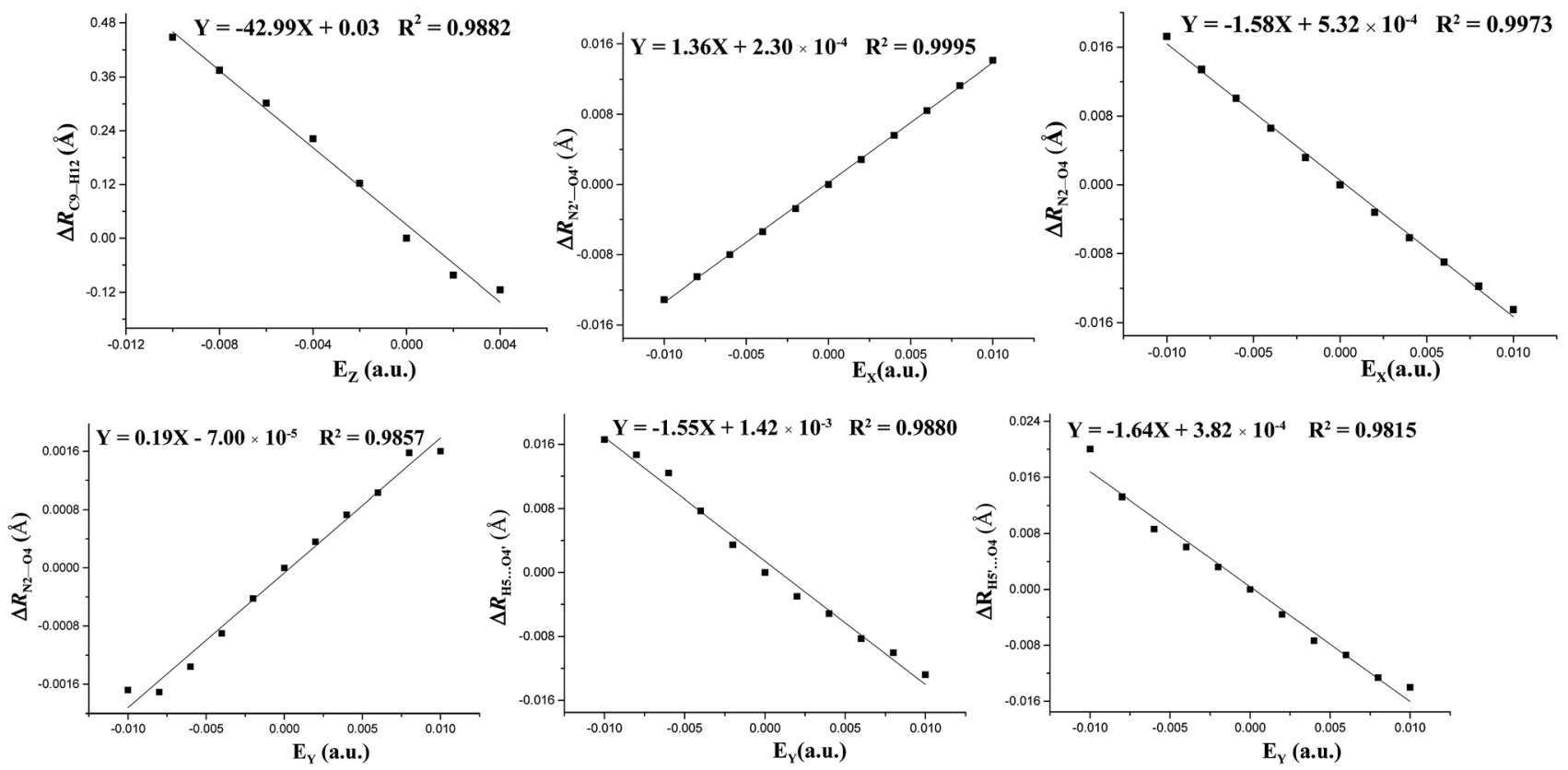

TS-3

Fig. 3 Changes of the bond lengths or interatomic distances versus field strengths in the different field orientations $\left(E_{X}, E_{Y}\right.$ and $\left.E_{Z}\right)$ for transition states at the MP2/6-311++G(2d,p) level.

hydrogen-bond distance is significantly altered by the field in the $z$-direction (see ESI data, Fig. S1 $\dagger$ ). In particular, when the field strength is larger than -0.0060 a.u. in the $-z$-direction or +0.0040 a.u. in the $+z$-direction, the $\mathrm{O}^{\prime} \cdots \mathrm{H} 5$ or $\mathrm{O} 4 \cdots \mathrm{H} 5^{\prime}$ distance is increased to 3.193 or $7.584 \AA$, i.e., the intermolecular $\mathrm{O} 4{ }^{\prime} \cdots \mathrm{H} 5$ (or $\mathrm{O} 4 \cdots \mathrm{H} 5^{\prime}$ ) hydrogen-bond is broken, and the sideby-side geometry is changed into the head-to-tail structure. In the $+y$-direction, an obvious trend that the dipoles antiparallel side-by-side geometry turns into the dipoles aligned side-byside structure is found.

The effects of fields on the geometries of TS3 are far weaker than those on the structures of reactants (see ESI data, Table S4 $\dagger$ ). All the TS3 structures are the dipoles antiparallel side-byside geometries in the absence and presence of external fields. 

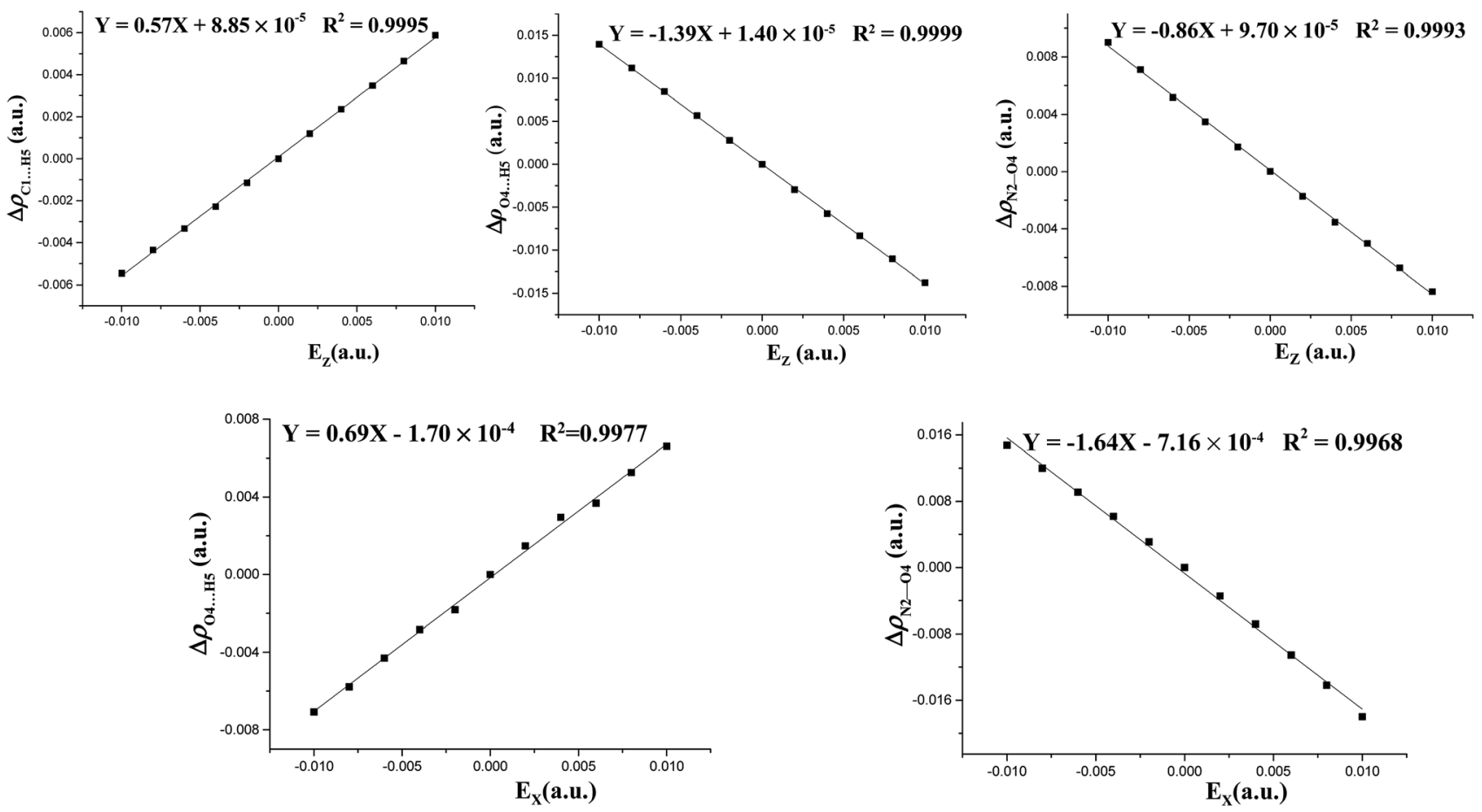

TS-2
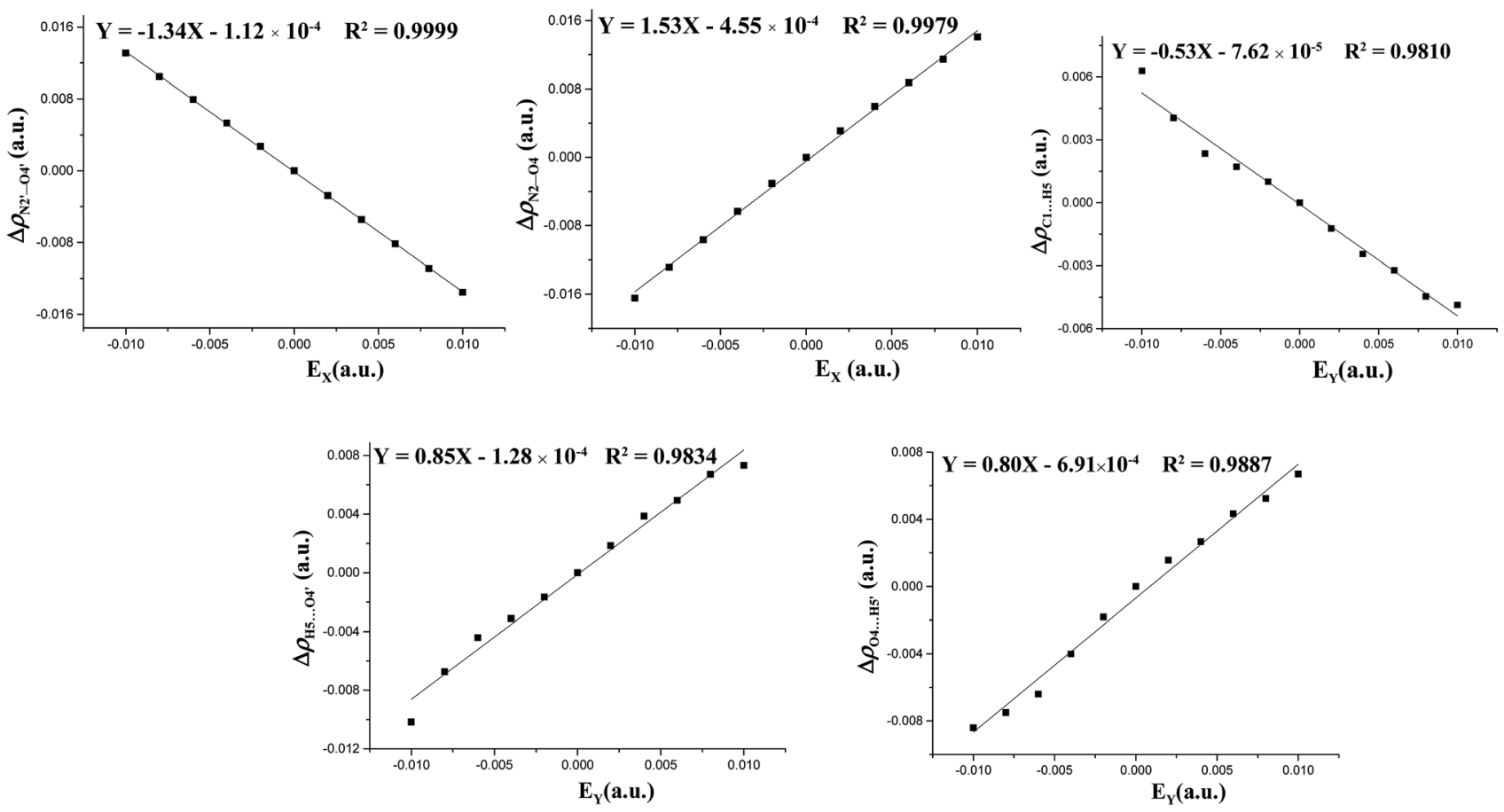

TS-3

Fig. 4 The changes of the electron densities versus field strengths in the different field orientations $\left(E_{X}, E_{Y}\right.$ and $\left.E_{Z}\right)$ for transition states at the MP2/ $6-311++G(2 d, p)$ level.

Furthermore, the fields parallel to the $z$ - and $y$-axes affect the structures of TS3 more than those parallel to the $x$-axis. As the field is increased in the $z$-direction, one of the $\mathrm{O} \cdots \mathrm{H}$ distances increases while the other one decreases. Similar changes of the
$\mathrm{C} \cdots \mathrm{H}$ distances are also found. In other words, with the increased fields in the $z$-direction, the double-proton transfer reaction turns into the single-proton transfer reaction. Indeed, from Fig. 1, when the field strength is up to 0.0100 a.u. in the $-z$ 
Table 1 Transition states imaginary frequencies $(I \mathrm{~m} v)$, Gibbs energies $\left(\Delta G, \mathrm{~kJ} \mathrm{~mol}^{-1}\right)$, reaction rate constants $\left(k, \mathrm{~s}^{-1}\right)$ and corrected reaction rate

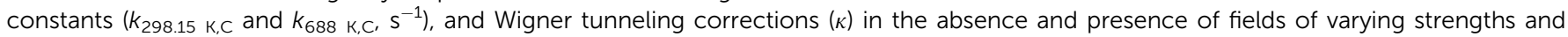
directions for the 1,3-intramolecular hydrogen transference path at the MP2/6-311++G(2d,p) level

\begin{tabular}{|c|c|c|c|c|c|c|c|c|c|}
\hline Field (a.u.) & $\operatorname{Im} v$ & $\Delta G_{298.15 \mathrm{~K}}$ & $k_{298.15 \mathrm{~K}}$ & $\kappa_{298.15 \mathrm{~K}}$ & $k_{298.15 \mathrm{~K}, \mathrm{C}}$ & $\Delta G_{688 \mathrm{~K}}$ & $k_{688 \mathrm{k}}$ & $\kappa_{688 \mathrm{~K}}$ & $k_{688 \mathrm{~K}, \mathrm{C}}$ \\
\hline No field & 2226.6 & 264.53 & $2.81 \times 10^{-34}$ & 5.849 & $1.64 \times 10^{-33}$ & 282.75 & $4.95 \times 10^{-9}$ & 1.903 & $9.42 \times 10^{-9}$ \\
\hline$Z-0.0100$ & 2090.1 & 261.12 & $1.11 \times 10^{-33}$ & 5.273 & $5.86 \times 10^{-33}$ & 272.67 & $2.88 \times 10^{-8}$ & 1.796 & $5.17 \times 10^{-8}$ \\
\hline$Z-0.0080$ & 2126.7 & 261.22 & $1.07 \times 10^{-33}$ & 5.424 & $5.79 \times 10^{-33}$ & 273.82 & $2.36 \times 10^{-8}$ & 1.824 & $4.30 \times 10^{-8}$ \\
\hline$Z-0.0060$ & 2156.3 & 261.58 & $9.23 \times 10^{-34}$ & 5.548 & $5.12 \times 10^{-33}$ & 275.30 & $1.82 \times 10^{-8}$ & 1.847 & $3.36 \times 10^{-8}$ \\
\hline$Z-0.0040$ & 2181.8 & 262.28 & $6.95 \times 10^{-34}$ & 5.656 & $3.93 \times 10^{-33}$ & 277.34 & $1.27 \times 10^{-8}$ & 1.867 & $2.38 \times 10^{-8}$ \\
\hline$Z-0.0020$ & 2206.0 & 263.29 & $4.64 \times 10^{-34}$ & 5.760 & $2.67 \times 10^{-33}$ & 279.86 & $8.20 \times 10^{-9}$ & 1.886 & $1.55 \times 10^{-8}$ \\
\hline$Z+0.0020$ & 2245.1 & 255.78 & $9.58 \times 10^{-33}$ & 5.930 & $5.68 \times 10^{-32}$ & 290.88 & $1.20 \times 10^{-9}$ & 1.918 & $2.29 \times 10^{-9}$ \\
\hline$Z+0.0040$ & 2260.1 & 256.08 & $8.49 \times 10^{-33}$ & 5.996 & $5.09 \times 10^{-32}$ & 253.16 & $8.72 \times 10^{-7}$ & 1.930 & $1.68 \times 10^{-6}$ \\
\hline$Z+0.0060$ & 2272.9 & 256.48 & $7.22 \times 10^{-33}$ & 6.053 & $4.37 \times 10^{-32}$ & 253.65 & $8.01 \times 10^{-7}$ & 1.941 & $1.55 \times 10^{-6}$ \\
\hline$Z+0.0080$ & 2284.1 & 256.98 & $5.91 \times 10^{-33}$ & 6.103 & $3.61 \times 10^{-32}$ & 254.20 & $7.27 \times 10^{-7}$ & 1.950 & $1.42 \times 10^{-6}$ \\
\hline$Z+0.0100$ & 2293.8 & 257.56 & $4.68 \times 10^{-33}$ & 6.146 & $2.87 \times 10^{-32}$ & 254.85 & $6.49 \times 10^{-7}$ & 1.958 & $1.27 \times 10^{-6}$ \\
\hline$X-0.0100$ & 2243.8 & 263.73 & $3.87 \times 10^{-34}$ & 5.924 & $2.29 \times 10^{-33}$ & 282.50 & $5.17 \times 10^{-9}$ & 1.917 & $9.92 \times 10^{-9}$ \\
\hline$X-0.0080$ & 2241.8 & 265.04 & $2.29 \times 10^{-34}$ & 5.915 & $1.35 \times 10^{-33}$ & 283.02 & $4.72 \times 10^{-9}$ & 1.915 & $9.04 \times 10^{-9}$ \\
\hline$X-0.0060$ & 2238.2 & 264.49 & $2.85 \times 10^{-34}$ & 5.900 & $1.68 \times 10^{-33}$ & 283.29 & $4.50 \times 10^{-9}$ & 1.912 & $8.61 \times 10^{-9}$ \\
\hline$X-0.0040$ & 2235.0 & 265.02 & $2.31 \times 10^{-34}$ & 5.886 & $1.36 \times 10^{-33}$ & 283.70 & $4.20 \times 10^{-9}$ & 1.910 & $8.01 \times 10^{-9}$ \\
\hline$X-0.0020$ & 2231.4 & 264.69 & $2.63 \times 10^{-34}$ & 5.870 & $1.54 \times 10^{-33}$ & 283.07 & $4.68 \times 10^{-9}$ & 1.907 & $8.93 \times 10^{-9}$ \\
\hline$X+0.0020$ & 2221.2 & 264.59 & $2.74 \times 10^{-34}$ & 5.825 & $1.60 \times 10^{-33}$ & 282.90 & $4.82 \times 10^{-9}$ & 1.899 & $9.16 \times 10^{-9}$ \\
\hline$X+0.0040$ & 2215.8 & 264.12 & $3.31 \times 10^{-34}$ & 5.802 & $1.92 \times 10^{-33}$ & 281.84 & $5.80 \times 10^{-9}$ & 1.894 & $1.10 \times 10^{-8}$ \\
\hline$X+0.0060$ & 2210.8 & 264.71 & $2.61 \times 10^{-34}$ & 5.780 & $1.51 \times 10^{-33}$ & 283.33 & $4.48 \times 10^{-9}$ & 1.890 & $8.46 \times 10^{-9}$ \\
\hline$X+0.0080$ & 2204.4 & 263.79 & $3.78 \times 10^{-34}$ & 5.753 & $2.17 \times 10^{-33}$ & 283.10 & $4.66 \times 10^{-9}$ & 1.885 & $8.78 \times 10^{-9}$ \\
\hline$X+0.0100$ & 2196.5 & 263.72 & $3.89 \times 10^{-34}$ & 5.719 & $2.22 \times 10^{-33}$ & 282.97 & $4.76 \times 10^{-9}$ & 1.879 & $8.95 \times 10^{-9}$ \\
\hline$Y-0.0100$ & 2246.3 & 260.84 & $1.24 \times 10^{-33}$ & 5.935 & $7.38 \times 10^{-33}$ & 274.10 & $2.24 \times 10^{-8}$ & 1.919 & $4.30 \times 10^{-8}$ \\
\hline$Y-0.0080$ & 2284.1 & 261.56 & $9.31 \times 10^{-34}$ & 6.103 & $5.68 \times 10^{-33}$ & 275.80 & $1.67 \times 10^{-8}$ & 1.950 & $3.25 \times 10^{-8}$ \\
\hline$Y-0.0060$ & 2237.3 & 266.80 & $1.13 \times 10^{-34}$ & 5.896 & $6.63 \times 10^{-34}$ & 287.85 & $2.03 \times 10^{-9}$ & 1.912 & $3.88 \times 10^{-9}$ \\
\hline$Y-0.0040$ & 2233.6 & 266.55 & $1.24 \times 10^{-34}$ & 5.879 & $7.30 \times 10^{-34}$ & 287.32 & $2.23 \times 10^{-9}$ & 1.909 & $4.25 \times 10^{-9}$ \\
\hline$Y-0.0020$ & 2230.1 & 265.98 & $1.56 \times 10^{-34}$ & 5.864 & $9.17 \times 10^{-34}$ & 286.11 & $2.75 \times 10^{-9}$ & 1.906 & $5.25 \times 10^{-9}$ \\
\hline$Y+0.0020$ & 2222.8 & 264.06 & $3.39 \times 10^{-34}$ & 5.832 & $1.98 \times 10^{-33}$ & 281.67 & $5.97 \times 10^{-9}$ & 1.900 & $1.13 \times 10^{-8}$ \\
\hline$Y+0.0040$ & 2220.0 & 262.75 & $5.75 \times 10^{-34}$ & 5.820 & $3.35 \times 10^{-33}$ & 278.70 & $1.00 \times 10^{-8}$ & 1.898 & $1.91 \times 10^{-8}$ \\
\hline$Y+0.0060$ & 2217.1 & 261.91 & $8.08 \times 10^{-34}$ & 5.808 & $4.70 \times 10^{-33}$ & 276.79 & $1.40 \times 10^{-8}$ & 1.895 & $2.66 \times 10^{-8}$ \\
\hline$Y+0.0080$ & 2213.3 & 261.38 & $9.98 \times 10^{-34}$ & 5.791 & $5.78 \times 10^{-33}$ & 275.59 & $1.73 \times 10^{-8}$ & 1.892 & $3.27 \times 10^{-8}$ \\
\hline$Y+0.0100$ & 2210.6 & 260.73 & $1.30 \times 10^{-33}$ & 5.780 & $7.51 \times 10^{-33}$ & 274.09 & $2.25 \times 10^{-8}$ & 1.890 & $4.25 \times 10^{-8}$ \\
\hline
\end{tabular}

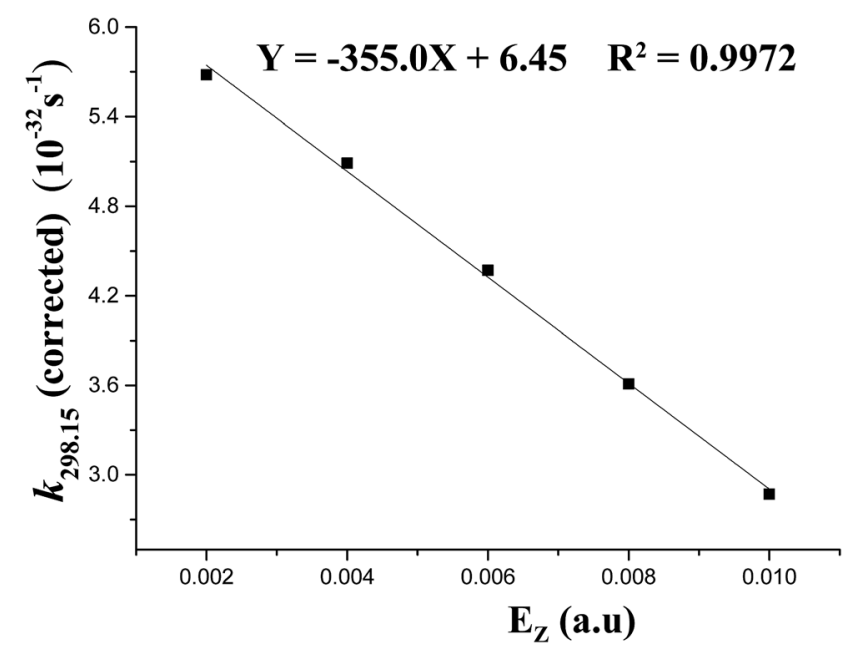

Fig. 5 Rate constant $\left(\mathrm{k}^{\mathrm{s}} \mathrm{s}^{-1}\right)$ at $298.15 \mathrm{~K}$ obtained from CTST after Wigner's tunneling correction versus field strengths in $z$-orientations for 1,3-intramolecular hydrogen transference at the MP2/6$311++G(2 d, p)$ level.

direction, one $\mathrm{O} \cdots \mathrm{H}$ distance is increased to $1.272 \AA$, and there exists only one imaginary frequency corresponding to this proton transfer. However, the other $\mathrm{O} \cdots \mathrm{H}$ distance is decreased to $1.010 \AA$, very close to the covalent bond length of $\mathrm{O}-\mathrm{H}$ bond, and no imaginary frequency mode corresponding to this hydrogen vibration is found. As the field is increased in the $+y$ direction, the $\mathrm{C} \cdots \mathrm{H}$ distances increases significantly and the $\mathrm{O} \cdots \mathrm{H}$ distances remarkably decreases. Fields in the $-y$ direction correspondingly show the opposite trends. From Table S4 (see ESI data $\dagger$ ), except for the $\mathrm{C} 1 \cdots \mathrm{H} 5, \mathrm{C}^{\prime} \cdots \mathrm{H} 5^{\prime}, \mathrm{O} 4^{\prime} \cdots \mathrm{H} 5$ and $\mathrm{O} 4 \cdots \mathrm{H} 5^{\prime}$ distances involving with the proton transfer, the other bond lengths are slightly altered by the fields. Fig. 3 shows several linear correlations between the changes of the bond lengths or the corresponding electron densities and field strengths with the linear correlation coefficients $R^{2}$ equal to the range of $0.9815-0.9995$ or $0.9810-0.9999$ along the $x$ - and $y$-oriented fields.

The energies of the reactants decrease while those of TS3 increase with increasing field strengths in the $\pm x$-, $+y$ - and $\pm z$-directions (see ESI data, Table S2 $\dagger$ ). Thus, the barriers increase. Furthermore, all the barriers are higher than the $\mathrm{C}-\mathrm{NO}_{2}$ BDEs, indicating that the fields in the $\pm x$-, $+y$ - and $\pm z$-directions cause preference of the $\mathrm{C}-\mathrm{NO}_{2}$ bond dissociation over the intermolecular hydrogen transference.

However, in the $-y$-direction, the barriers of the intermolecular hydrogen transference reactions are lower than the C$\mathrm{NO}_{2}$ BDEs (see Fig. 2), suggesting that the applied field in the 
$-y$-direction causes preference of the intermolecular hydrogen transference reaction over the $\mathrm{C}-\mathrm{NO}_{2}$ bond dissociation. Although the energies of reactant and TS3 decrease with increasing field strength in the $-y$-direction, the energies of TS3 decrease more significantly than those of reactant (see ESI data, Table S2 $\uparrow$ ), and hence the barrier heights are decreased. At the maximal field strength, the barrier height is lowered to $14.38 \%$ of its field-free value.

Fields oriented parallel to the $x$ - or $y$-axis have a minor effect on the imaginary frequency. However, fields along the $z$-axis have a significant effect on the imaginary vibration. The imaginary vibrations decrease: from its field-free value 1955.4 to $1396.7 \mathrm{~cm}^{-1}$ at maximal field strength (see Table 2). The magnitude of the imaginary frequency decreases by $28.6 \%$ under the influence of the maximal field intensity in the $z$-direction when compared to the zero-field case. Thus, a fieldinduced flattening of the potential energy surface is suggested. From Table 2, at $298.15 \mathrm{~K}$, the Wigner corrections in the $x$ - and $z$-directions is notable (about 4.3-5.3).

To sum up, in conjunction with our previous study on " $\mathrm{CH}_{3} \mathrm{NO}_{2} \rightarrow \mathrm{CH}_{3} \mathrm{ONO}$ " via TS1, ${ }^{11}$ the barriers of three reaction paths are all higher than the $\mathrm{C}-\mathrm{NO}_{2}$ BDEs in the $x$-oriented fields. Thus, the $x$-oriented fields do not induce the change of the reaction pathways relative to those in the absence of field, ${ }^{19}$ and the $\mathrm{C}-\mathrm{NO}_{2}$ bond scission is always kinetically favored. Therefore, in the $x$-oriented fields, the explosive sensitivity of $\mathrm{CH}_{3} \mathrm{NO}_{2}$ can be evaluated by the strength of the $\mathrm{C}-\mathrm{NO}_{2}$ bond. The $\mathrm{C}-\mathrm{NO}_{2}$ BDEs remain nearly unchanged in the external electric fields $\left(275.38-280.90 \mathrm{~kJ} \mathrm{~mol}^{-1}\right.$ in $x$-direction), indicating that the explosive sensitivity remains nearly unchanged in the $x$-oriented external electric fields. Furthermore, the sensitivities are almost equal to those in the absence of field since the $\mathrm{C}-\mathrm{NO}_{2}$ BDEs in the $x$-oriented fields are very close to that in the absence of external field.

However, when the field is in the $-y$-direction of dimer, due to the lower barriers than the $\mathrm{C}-\mathrm{NO}_{2}$ BDEs, intermolecular hydrogen transference reaction occur preferentially over the $\mathrm{C}-\mathrm{NO}_{2}$ bond scission. In the $-y$-direction, the explosive sensitivity can be evaluated by the strength of the $\mathrm{C}-\mathrm{H}$ bond and the $\mathrm{C}-\mathrm{H}$ bond becomes the trigger linkage. Our recent investigation shows that when the field strength is larger than +0.0060 a.u. in the $+z$ direction, the $\mathrm{CH}_{3} \mathrm{NO}_{2} \rightarrow \mathrm{CH}_{3} \mathrm{ONO}$ reaction occur preferentially. ${ }^{11}$ Thus, when the field strength is larger than +0.0060 a.u. in the $+z$-direction of $\mathrm{CH}_{3} \mathrm{NO}_{2}$ or the field is in the $-y$-direction of dimer, the detonation initiation occurs more easily and thus the explosive sensitivities are increased in comparison with those in the absence of external electric field. In the other fields along the $y$ and $z$-orientations, the $\mathrm{C}-\mathrm{NO}_{2} \mathrm{BDEs}$ are all lower than the barriers of above three reaction paths, and the $\mathrm{C}-\mathrm{NO}_{2}$ bond scission is kinetically favored (see Fig. 2). Thus, the sensitivities are almost equal to those in the absence of external electric field since the $\mathrm{C}-\mathrm{NO}_{2}$ BDEs in the external electric fields of $y$ - and $z$-directions $\left(274.97-275.90 \mathrm{~kJ} \mathrm{~mol}^{-1}\right)$ are almost equal to those in no field.

Since, in theory, the change of the directions and strengths of external electric fields can alter the reaction pathways and thus change the explosive stability and sensitivity, can the stability and sensitivity of explosive be adjusted with external electric field in practice? At present, thus proposition does not make any sense for four reasons at least: (1) one can not specify (let alone control) the orientation of a macroscopic sample of explosive that are randomly oriented in gas, solid or liquid solution form with respect to an externally-applied field. (2) One can not find out the electromagnetic (EM) field applied to the system in this paper. These are several orders of magnitude below any fields that can have any effect on barriers or energies of reactions - to have an effect an applied field must have at least a strength of $10^{7}$ or $10^{8}$ volts per $\mathrm{m}$ way stronger than an macroscopic field that can be achieved on a macroscopic sample whether intentionally or from stray EM fields. Therefore, the experiments that the external electric fields are imposed to energetic materials can be not designed. (3) The system studied in this paper is a single $\mathrm{CH}_{3} \mathrm{CO}_{2}$ molecule or a $\mathrm{H}$-bonded complex formed by two $\mathrm{CH}_{3} \mathrm{CO}_{2}$ molecules in gas phase. In reality, the $\mathrm{CH}_{3} \mathrm{CO}_{2}$ molecule may also exist in an oily liquid state or a solid state under different conditions. Furthermore, for each of three states, there would be an increased probability of alignment along the electric field in competition with kinetic translational and rotational motion in the presence of an electric field. Moreover, this would have a temperature dependence: in general, the higher the temperature, the larger this probability would be. However, as mentioned above, the electric field in different directions has different effects on the stability and sensitivity of the explosive molecules. In other words, only the molecule is exposed to a particular direction of the field relative to its own orientation, would there be an increased chance of ignition. At a particular temperature, these results follow the probabilistic distribution of statistical mechanical sense. Here, a molecular dynamics calculation was performed with Materials Studio 7.0 program. ${ }^{35}$ The molecular number of $\mathrm{CH}_{3} \mathrm{NO}_{2}$ was set to 12 , and the placement of 12 molecules consist of two patterns: random and all the molecules regularly pointing to the same direction. In the $x$-axis direction, the external electric field strength of 0.006 a.u. was considered. For the second pattern, the $\mathrm{C} \cdots \mathrm{NO}_{2}$ orientation was on the $x$-axis (see Fig. 6). The temperature was set as 298 , $350,500,900,1800 \mathrm{~K}$, respectively. Then, these models were considered as NVT ensembles to make MD simulations by CASTEP module. The finally equilibrium structures for two patterns were obtained at all the temperatures. Furthermore, the single point energy of the random pattern was higher than that of the pattern that all the molecules pointed to the same direction at each of the temperatures, indicating that the latter was more stable than the former. These results indirectly confirm that the molecules have an increased tendency to align along the field and the increased chance of ignition follows the probabilistic distribution of statistical mechanical sense in the external electric field at a particular temperature. (4) The decomposition process of nitromethane itself is very complex. For example, a recent ReaxFF molecular dynamics simulation has indicated that the fragments from the decomposition of nitromethane, like $\mathrm{H}_{2} \mathrm{O}, \mathrm{NO}, \mathrm{NO}_{2}$, $\mathrm{HONO}$, play a role of catalysis. Furthermore, the decomposition of nitromethane can lead to many different structures of carbon clusters, and the configuration of cluster is dependent on external conditions. ${ }^{36}$ 
Table 2 Transition states imaginary frequencies $(\mathrm{Im} v)$, Gibbs energies $\left(\Delta G, \mathrm{~kJ} \mathrm{~mol}^{-1}\right)$, reaction rate constants $\left(k, \mathrm{~s}^{-1}\right)$ and corrected reaction rate

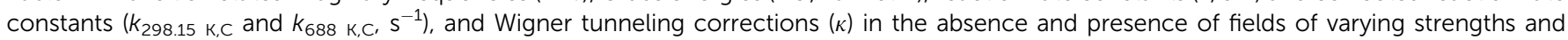
directions for the intermolecular hydrogen transference path at the MP2/6-311++G(2d,p) level

\begin{tabular}{|c|c|c|c|c|c|c|c|c|c|}
\hline Field (a.u.) & $\operatorname{Im} v$ & $\Delta G_{298.15 \mathrm{~K}}$ & $k_{298.15 \mathrm{~K}}$ & $\kappa_{298.15 \mathrm{~K}}$ & $k_{298.15 \mathrm{~K}, \mathrm{C}}$ & $\Delta G_{688 \mathrm{~K}}$ & $k_{688 \mathrm{~K}}$ & $\kappa_{688 \mathrm{~K}}$ & $k_{688 \mathrm{~K}, \mathrm{C}}$ \\
\hline No field & 1955.4 & 266.93 & $1.06 \times 10^{-34}$ & 4.740 & $5.04 \times 10^{-34}$ & 329.82 & $1.32 \times 10^{-12}$ & 1.696 & $2.25 \times 10^{-12}$ \\
\hline$Z-0.0100$ & 1396.7 & 280.96 & $3.71 \times 10^{-37}$ & 2.908 & $1.08 \times 10^{-36}$ & 344.29 & $1.06 \times 10^{-13}$ & 1.355 & $1.43 \times 10^{-13}$ \\
\hline$Z-0.0060$ & 1547.2 & 273.10 & $8.84 \times 10^{-36}$ & 3.341 & $2.95 \times 10^{-35}$ & 325.25 & $2.94 \times 10^{-12}$ & 1.436 & $4.22 \times 10^{-12}$ \\
\hline$Z-0.0040$ & 1618.9 & 263.18 & $4.84 \times 10^{-34}$ & 3.563 & $1.72 \times 10^{-33}$ & 341.40 & $1.75 \times 10^{-13}$ & 1.477 & $2.58 \times 10^{-13}$ \\
\hline$Z-0.0020$ & 1807.1 & 265.44 & $1.95 \times 10^{-34}$ & 4.194 & $8.17 \times 10^{-34}$ & 330.98 & $1.08 \times 10^{-12}$ & 1.595 & $1.72 \times 10^{-12}$ \\
\hline$Z+0.0060$ & 273.3 & 291.26 & $5.82 \times 10^{-39}$ & 1.073 & $6.24 \times 10^{-39}$ & 362.20 & $4.61 \times 10^{-15}$ & 1.014 & $4.68 \times 10^{-15}$ \\
\hline$Z+0.0080$ & 1468.4 & 280.31 & $4.83 \times 10^{-37}$ & 3.109 & $1.50 \times 10^{-36}$ & 346.22 & $7.53 \times 10^{-14}$ & 1.393 & $1.05 \times 10^{-13}$ \\
\hline$Z+0.0100$ & 1396.7 & $-^{a}$ & - & 2.908 & - & - & - & 1.355 & - \\
\hline$X-0.0100$ & 2019.5 & $-^{a}$ & - & 4.989 & - & - & - & 1.743 & - \\
\hline$X-0.0080$ & 2008.7 & $-^{a}$ & - & 4.946 & - & - & - & 1.735 & - \\
\hline$X-0.0060$ & 1994.4 & 259.27 & $2.34 \times 10^{-33}$ & 4.890 & $1.14 \times 10^{-32}$ & 307.95 & $6.05 \times 10^{-11}$ & 1.724 & $1.04 \times 10^{-10}$ \\
\hline$X+0.0060$ & 1924.6 & 269.82 & $3.32 \times 10^{-35}$ & 4.623 & $1.53 \times 10^{-34}$ & 343.46 & $1.22 \times 10^{-13}$ & 1.675 & $2.04 \times 10^{-13}$ \\
\hline$X+0.0080$ & 1919.3 & 269.64 & $3.57 \times 10^{-35}$ & 4.603 & $1.64 \times 10^{-34}$ & 342.13 & $1.54 \times 10^{-13}$ & 1.671 & $2.57 \times 10^{-13}$ \\
\hline$X+0.0100$ & 1914.8 & 258.25 & $3.53 \times 10^{-33}$ & 4.586 & $1.62 \times 10^{-32}$ & 306.27 & $8.12 \times 10^{-11}$ & 1.668 & $1.35 \times 10^{-10}$ \\
\hline$Y-0.0100$ & 2087.4 & 220.66 & $1.36 \times 10^{-26}$ & 5.262 & $7.16 \times 10^{-26}$ & 343.69 & $1.17 \times 10^{-13}$ & 1.794 & $2.10 \times 10^{-13}$ \\
\hline$Y-0.0080$ & 2058.5 & 231.38 & $1.80 \times 10^{-28}$ & 5.144 & $9.26 \times 10^{-28}$ & 339.78 & $2.32 \times 10^{-13}$ & 1.772 & $4.12 \times 10^{-13}$ \\
\hline$Y-0.0060$ & 2034.3 & 241.25 & $3.36 \times 10^{-30}$ & 5.048 & $1.70 \times 10^{-29}$ & 336.15 & $4.38 \times 10^{-13}$ & 1.754 & $7.67 \times 10^{-13}$ \\
\hline$Y-0.0040$ & 2008.5 & 250.35 & $8.54 \times 10^{-32}$ & 4.945 & $4.22 \times 10^{-31}$ & 332.97 & $7.63 \times 10^{-13}$ & 1.735 & $1.32 \times 10^{-12}$ \\
\hline$Y-0.0020$ & 1981.9 & 258.51 & $3.18 \times 10^{-33}$ & 4.842 & $1.54 \times 10^{-32}$ & 329.87 & $1.31 \times 10^{-12}$ & 1.715 & $2.25 \times 10^{-12}$ \\
\hline$Y+0.0020$ & 1919.7 & 273.10 & $8.86 \times 10^{-36}$ & 4.604 & $4.08 \times 10^{-35}$ & 326.76 & $2.26 \times 10^{-12}$ & 1.671 & $3.78 \times 10^{-12}$ \\
\hline$Y+0.0040$ & 1906.2 & 278.97 & $8.29 \times 10^{-37}$ & 4.554 & $3.78 \times 10^{-36}$ & ${ }^{a}$ & - & 1.662 & - \\
\hline$Y+0.0060$ & 1884.6 & 281.96 & $2.48 \times 10^{-37}$ & 4.474 & $1.11 \times 10^{-36}$ & 333.15 & $7.40 \times 10^{-13}$ & 1.647 & $1.22 \times 10^{-12}$ \\
\hline$Y+0.0080$ & 1858.6 & 284.89 & $7.62 \times 10^{-38}$ & 4.379 & $3.34 \times 10^{-37}$ & 329.98 & $1.29 \times 10^{-12}$ & 1.629 & $2.10 \times 10^{-12}$ \\
\hline
\end{tabular}

${ }^{a}$ IRC involving the transformation from a side-by-side geometry nitromethanol dimer to a side-by-side geometry aci-nitromethane dimer is not found.

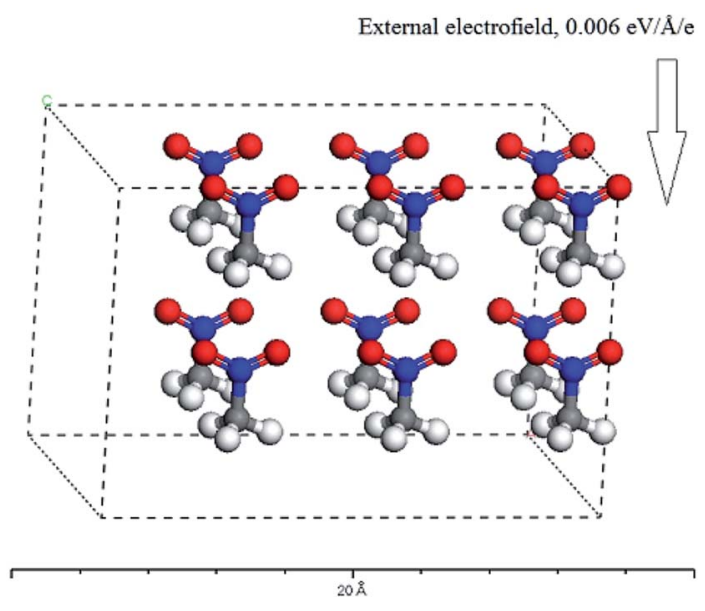

Fig. 6 The equilibrium structure in the external electric field for the pattern that all the molecules regularly point to the same direction.

To date there are still many obstacles to add external electric field into energetic material system in experiment. However, the external electric field effect itself of changing the reaction pathways and stability (sensitivity) of explosive is remarkable enough to arouse the intense interest of researchers and keep them full of confidence to achieve experimental goals in energetic material field, since the orientation of molecules could be determined by Langmuir-Blodgett techniques, ${ }^{37,38}$ and the investigations on electron transports of molecular-scale systems have been launched in experiment. ${ }^{39}$ Furthermore, the observation of large reversible switching behavior in the electronic device that uses molecules as the active component has been reported..$^{40-42}$

\section{Conclusions}

The effects of external electric field on the detonation initiation reaction dynamics of $\mathrm{CH}_{3} \mathrm{NO}_{2}$ were investigated by the MP2 and CCSD methods. The results show that a new bimolecular intermolecular hydrogen transference mechanism, from a sideby-side nitromethane dimer formed by two intermolecular $\mathrm{H}$ bonding interactions to a side-by-side aci-nitromethane dimer, is the most favored bimolecular reaction pathway. Furthermore, this pathway occurs in the most competition with the $\mathrm{C}-\mathrm{NO}_{2}$ bond rupture at the initial stage of $\mathrm{CH}_{3} \mathrm{NO}_{2}$ 
decomposition in the absence of external electric field. Some linear correlations between the changes of bond lengths or electron densities and field strengths in different field orientations are obtained.

In particular, when the field is in the $-y$-direction of $\mathrm{CH}_{3} \mathrm{NO}_{2}$ dimer (the orientation perpendicular to the $\mathrm{O} \cdots \mathrm{N} \cdots \mathrm{N}$ plane), the barriers of intermolecular hydrogen transference are lower than the $\mathrm{C}-\mathrm{NO}_{2}$ BDEs. Therefore, when the field in the $-y$ direction causes preference of the intermolecular hydrogen transference reaction. In the $-y$-direction, the $\mathrm{C}-\mathrm{H}$ bond may be trigger linkage. Furthermore, in this case, the explosive sensitivities are increased in comparison with those in the absence of field. However, in the other fields, the barriers of hydrogen transference reaction paths are all higher than the $\mathrm{C}-\mathrm{NO}_{2}$ BDEs. Thus, the fields do not induce the change of the reaction pathways relative to those in the absence of external electric field and the $\mathrm{C}-\mathrm{NO}_{2}$ bond scission is kinetically favored in initiating detonation. In these cases, the explosive sensitivities can be evaluated by the strength of the $\mathrm{C}-\mathrm{NO}_{2}$ bond and they are almost equal to those in the absence of external electric field. The change of the directions and strengths of external electric fields can change the reaction pathways and stabilities (sensitivities) of explosives. This theoretical investigation must be useful to safely add external electric field into energetic material systems to increase the energy, detonation velocity and detonation pressure in future.

\section{Conflicts of interest}

The authors declare no conflicts of interest for this work.

\section{References}

1 D. Tasker, The properties of condensed explosives for electromagnetic energy coupling, NSWC T.R., 1985, pp. 85-360.

2 D. Demske, The experimental aspects of coupling electrical energy into a dense detonation wave: Part 1, NSWC T.R., 1982, pp. 79-143.

3 T. Piehler, C. Hummer, R. Benjamin, E. Summers, K. McNesby and V. Boyle, Preliminary study of coupling electrical energy to detonation reaction zone of primasheet1000 explosive, 27th International Symposium on Ballistics, Freiburg, Germany, 2013, pp. 22-26.

4 P. Politzer, J. S. Murray, M. C. Concha and P. Lane, Cent. Eur. J. Energ. Mater., 2007, 4, 3-21.

5 P. Politzer, J. S. Murray and P. Lane, Int. J. Quantum Chem., 2009, 109, 534-539.

6 J. S. Li, J. Hazard. Mater., 2010, 180, 768-772.

7 C. Z. Cao and S. Gao, J. Phys. Chem. B, 2007, 111, 1239912402.

8 J. Zhao, X. L. Cheng, B. He and X. D. Yang, Struct. Chem., 2006, 17, 501-507.

9 B. S. Tan, X. P. Long, R. F. Peng, H. B. Li, B. Jin, S. J. Chu and H. S. Dong, J. Hazard. Mater., 2010, 183, 908-912.

10 A. A. Arabi and C. F. Matta, Phys. Chem. Chem. Phys., 2011, 13, 13738-13748.

11 F.-d. Ren, D.-l. Cao and W.-j. Shi, J. Mol. Model., 2016, 22, 96.
12 J. B. Pedley, R. D. Naylor and S. P. Kirby, Thermochemical data of organic compounds, Chapman, New York, 2nd edn, 1986.

13 D. Margetis, E. Kaxiras, M. Elstner, T. Frauenheim and M. R. Manaa, J. Chem. Phys., 2002, 117, 788-799.

14 M. Citroni, R. Bini, M. Pagliai, G. Cardini and V. Schettino, J. Phys. Chem. B, 2010, 114, 9420-9428.

15 S. P. Han, A. C. T. van Duin, W. A. Goddard and A. Strachan, J. Phys. Chem. B, 2011, 115, 6534-6540.

16 F. Guo, X. Cheng and H. Zhang, J. Phys. Chem. A, 2012, 116, 3514-3520.

17 T. L. Cottrell, T. E. Graham and T. J. Reid, Trans. Faraday Soc., 1951, 47, 1089-1092.

18 J. Chang, P. Lian, D. Q. Wei, X. R. Chen, Q. M. Zhang and Z. Z. Gong, Phys. Rev. Lett., 2010, 105, 188302-188305.

19 W. F. Hu, T. J. He, D. M. Chen and F. C. Liu, J. Phys. Chem. A, 2002, 106, 7294-7303.

20 F.-d. Ren, D.-l. Cao, W.-j. Shi, M. You and M. Li, J. Mol. Model., 2015, 21, 145-153.

21 M. J. Frisch, et al., Gaussian 03, Revision B.03, Gaussian, Inc., Pittsburgh PA, 2003.

22 R. F. W. Bader, Atoms in molecules, a quantum theory, Oxford University Press, Oxford, UK, 1990.

23 F. W. B. König, R. F. W. Bader and T. H. Tang, J. Comput. Chem., 1982, 3, 317-328.

24 C. J. Cramer, Essentials of Computational Chemistry: Theories and Models, John Wiley \& Sons, Ltd., New York, 2002.

25 J. I. Steinfeld, J. S. Fransisco and W. L. Hase, Chemical Kinetics and Dynamics, Prentice Hall, New Jersey, 2nd edn, 1999.

26 E. P. Wigner, Z. Phys. Chem., Abt. B, 1932, 19, 203-216.

27 H. Eyring and E. M. Eyring, Modern Chemical Kinetics, Reinhold Publishing Corporation, New York, 1963.

28 S. Glasstone, K. J. Laidler and H. Eyring, The Theory of Rate Processes, McGraw-Hill Book Company, Inc., New York, 1st edn, 1941.

29 R. D. Bardo, Ninth symposium (international) on detonation, Office of Naval Research, Arlington, 1989, p. 235.

30 R. D. Bardo, Eighth symposium (international) on detonation, Naval Surface Weapons Center, White Oak, 1985, p. 855.

31 M. D. Cook, J. Fellows and P. J. Haskins, Decomposition, Combustion, and Detonation Chemistry of Energetic Materials, Materials Research Society, Symposium Proceedings, Materials Research Society, Pittsburgh, 1996, vol. 48, pp. 267-275.

32 J. M. Winey and Y. M. Gupta, J. Phys. Chem. B, 1997, 101, 9333-9340.

33 S. Zeman, T. Atalar, Z. Friedl and X.-H. Ju, Cent. Eur. J. Energ. Mater., 2009, 6, 119-133.

34 E. B. Burgina, V. P. Baltakhinov, E. V. Boldyreva, E. S. Stoyanov, N. Y. Zhanpeisov and G. M. Zhidomirov, J. Mol. Struct., 1993, 296, 53-59.

35 Accelrys Software Inc., Materials Studio 7.0., San Diego, 2013. 36 L. Zhang and L. Chen, Acta Phys. Sin., 2013, 62, 138201138210.

37 K. Arnold, D. Hoekstra and S. Ohki, Biochim. Biophys. Acta, 1992, 1124, 88-94.

38 H. Brockman, Curr. Opin. Struct. Biol., 1999, 9, 438-443. 
39 L. Benitez, D. Cristancho, J. M. Seminario, J. M. Martinez de la Hoz and P. B. Balbuena, Electrochim. Acta, 2014, 140, 250257.

40 J. Chen, M. A. Reed, A. M. Rawlett and J. M. Tour, Science, 1999, 286, 1550-1552.
41 M. A. Reed, C. Zhou, C. J. Muller, T. P. Burgin and J. M. Tour, Science, 1997, 278, 252-254.

42 J. Chen, W. Wang, M. A. Reed, A. M. Rawlett, D. W. Price and J. M. Tour, Appl. Phys. Lett., 2000, 77, 1224-1226. 